\title{
Cyclical Vomiting Syndrome in Children
}

\author{
Rimjhim Shrivastava* \\ Pediatric Gastroenterologist and Hepatologist, India
}

*Corresponding author: Dr. Rimjhim Shrivastava, Pediatric Gastroenterologist and Hepatologist,Ekta Institute of Child Health, New Shanti Nagar, Raipur, Chhattisgarh, India

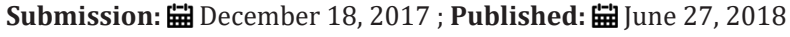

Keywords: Cyclical vomiting syndrome; Endoscopy; Propranolol; Amytriptiline

\section{Introduction}

Cyclic vomiting is considered a variant of migraine, first described by Gee in 1881[1]. Cyclic vomiting syndrome (CVS) is a disorder characterized by recurrent, discrete, self-limited episodes of vomiting and is defined by symptom-based criteria and the absence of positive laboratory, radiographic, and endoscopic testing [2]. The attacks of vomiting are interspersed with normal periods. The duration of vomiting episodes is from hours to days, with spontaneous resolution if left untreated. The episodic occurrence of emesis may be precipitated by stress and fatigue. The attacks begin in childhood and often wane in frequency with progression into young and middle adult life [3].The differential diagnoses include idiopathic CVS, gastrointestinal disorders, and extraintestinal disorders, including brain stem neoplasm, abdominal epilepsy, and metabolic disorders.

\section{Etiopathogenesis}

The etio-pathogenesis remain unknown but there appears to be a strong link between CVS and migraine, based upon similarities in symptoms, common coexistence of both conditions in the same individual, a high family prevalence of migraine in patients with CVS, and the effectiveness of antimigraine therapy [4]. Proposed mechanisms by which CVS occurs are based primarily on clinical observations of CVS and related conditions.

Mitochondrial gene mutations, stress induced release of cotropin-releasing-factor resulting in secretion ofACTH, thereby activating the hypophyseal-pituitary-adrenal axis (HPA) and the stress response, gastrointestinal motility disorders ,sympathetic hype-responsivity and autonomic dysfunction, genetic associations, food allergy are some of the suggested etiologies[5].

\section{Clinical Features of CVS [5]}

\section{The interepisodic phase}

It is more or less symptom free.

\section{The prodromal phase}

The patient senses the approach of an episode during thisphase but is still able to take and retain oral medications. Prodromal symptoms consist of nausea, lethargy, anorexia, pallor, abdominal pain etc. A migraine-like visual aura is rare.

\section{The vomiting phase}

It is characterized by intense, persistent nausea, vomiting, retching, and other symptoms. The symptoms are overwhelming and completely incapacitating. The maximum frequency of vomiting may be more than 10 times per hour.

Signs and symptoms of an intense stress response are common, including increased heart rate and blood pressure, drenching diaphoresis, minor loose stooling, low-grade fever etc.

\section{The recovery phase}

It begins as soon as nausea remits and ends when the patient has recovered appetite, strength, and body weight lost during the vomiting phase.

\section{Frequency of CVS Episodes}

The frequency of CVS episodes ranges from 1 to 70 episodes per year with an average of 12 episodes a year. Patients with uncomplicated CVS are asymptomatic between episodes; attacks have an "on-off" pattern. About half of the patients have fairly regular recurrences that are more or less predictable. Each episode tends to be stereotypical and characteristic for each patient in terms of time of onset, intensity, episode duration, and associated symptoms. Vomiting typically begins either during the night, waking the patient from sleep, or occurs in the morning; nevertheless, some patient have variable times of onset [5].

\section{Precipitating Factors for CVS[6]}

\section{Stress}

Physical:infections, sleep deprivation, exercise, trauma

Emotional: holidays, birthdays, family vacations, festivals,school camps, examinations, familial conflicts, anxiety

\section{Menstruation}

Food allergies 


\section{Diagnosis}

The diagnosis of CVS requires exclusion of other known and treatable disorders. When a patient presents with acute vomiting, severe disorders can usually be excluded by history, physical examination, and basic laboratory studies such as a complete blood count and a complete metabolic panel including liver function tests, amylase, and lipase, a urinalysis, and an upper GI series/small bowel follow through.

Abdominal ultrasound of the liver, gall bladder, pancreas, kidneys, and adrenals may help in evaluation of possible gallstones, pancreatitis, and ureteropelvicjunction obstruction.

An Upper GI Endoscopy needs to be performed in patients with acute vomiting, often for hematemesis or on clinical suspicion of peptic ulcer disease. If the above tests are negative, structural lesions need to be excluded with imaging studies such as head and abdominal CT. An EEG may be obtained depending upon the clinical suspicion of seizure disorder. In the case of patients presenting with cyclic symptoms of vomiting, metabolic disorders including pituitary-adrenal disorders, organic acid, and amino acid disorders need to be screened for.

\section{Diagnostic Criteria For CVS[5]}

North American Society for Paediatric Gastroenterology, Hepatology, and Nutrition (NASPGHN) proposed the following criteria:

At least 5 attacks in any interval, or a minimum of 3 attacks during a $6 \mathrm{mo}$ period (all of the following must be met)

a. Episodic attacks of intense nausea and vomiting lasting 1h-10 days and occurring at least $1 \mathrm{wk}$ apart.

b. Stereotypical pattern and symptoms in the individual patient.

c. Vomiting during attacks occurs at least 4 times/h for at least 1 hour.

d. Return to baseline health between episodes.

e. Not attributed to another disorder.

\section{Treatment [7]}

No standard evidence-based regimen currently exists to manage CVS. Most of the information in the literature is based on anecdotal evidence. Treatment is usually individualized and often is a trial and error process. Management is based on the four phases of CVS.

\section{The interepisodic phase}

The therapeutic goal during this phase is prophylaxisprevent further episodes. Medications used for prophylaxis include cyproheptadine, propranolol and tricyclic antidepressants.

\section{The prodromal phase}

Abortive therapy is used during the prodromal phase when the patient begins to sense early nausea signaling the approach of vomiting, but is still able to take and retain oral medications. Patients prefer a dark, quiet nonstimulating environment,which can be initiated as soon as any prodromal signs occur. Many antiemetic agents have been proven to be clinically beneficial; specifically, agents such as ondansetron and promethazine in combination with diphenhydramine have been successful

\section{The vomiting phase}

The goal is toprevent dehydration and terminate the nausea and vomiting. Intravenous ondansetron or lorazepam can be used. Patient should be kept in a quiet and calm place with dim light.

\section{The recovery phase}

The goal is to refeed the patient without causing a relapse of nausea.

\section{Prognosis}

Most published series indicate that cyclic vomiting syndrome lasts an average of 2.5-5.5 years, resolving in late childhood or early adolescence. A few patients continue to be symptomatic through adulthood. Migraine headache, abdominal migraine, and CVS seem to be manifestations of migraine diathesis. The distinction of these three syndromes is based on their predominant symptoms: headachepredominates in migraine; intense, sustained, midline abdominal pain predominates in abdominal migraine; and nausea and vomiting predominate in CVS[7].

\section{References}

1. Lanzi G, Balottin U, Ottolini A, Burgio FR, Fazzi E, et al. (1983) Cyclic vomiting and recurrent abdominal pains as migraine or epileptic equivalents. Cephalalgia 3(2): 115-118.

2. Gee S (1881) On fitful or recurrent vomiting. St Bartolomews Hosp Reports 18: 1-6.

3. Cyclical Vomiting Syndrome Association (1995) International diagnostic criteria for cyclic vomiting syndrome. J Pediatr Gastroenterol Nutr 21(suppl 1).

4. Sato T, Igarashi N, Minami S (1988) Recurrent attacks of vomiting, hypertension and psychotic depression: A syndrome of periodic catecholamine and prostaglandin discharge. Acta Endocrinol (Copenh) 117(2): 189-197.

5. Li BU, Balint JP (2000) Cyclic vomiting syndrome: Evolution in our understanding of a brain-gut disorder. Adv Pediatr 47: 1-44.

6. Withers GD, Silburn SR, Forbes DA (1998) Precipitants and aetiology of cyclic vomiting syndrome. Acta Paediatr 87 (3): 272-277.

7. Li BU, Lefevre F, Chelimsky GG, Boles RG, Nelson SP, et al. (2008) North American Society for Pediatric Gastroenterology, Hepatology, and Nutrition consensus statement on the diagnosis and management of cyclic vomiting syndrome. J Pediatr Gastroenterol Nutr 47 (3):3 79-393. 
Creative Commons Attribution 4.0 International License

For possible submissions Click Here

Submit Article

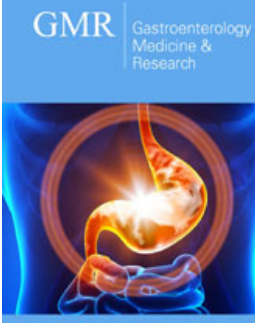

Gastroenterology Medicine \& Research

\section{Benefits of Publishing with us}

- High-level peer review and editorial services

- Freely accessible online immediately upon publication

- Authors retain the copyright to their work

- Licensing it under a Creative Commons license

- Visibility through different online platforms 